\title{
RENAL GLOMERULAR NUMBER AND SIZE IN AUSTRALIAN ABORIGINES, AFRICAN AMERICANS AND WHITE POPULATIONS FROM THE SAME LOCATIONS: A PRELIMINARY REPORT
}

\author{
JOHN F BERTRAM ${ }^{1}$, KELLI JOHNSON ${ }^{1 \#}$, MiCHAEL D HuGHSON ${ }^{2}$ AND WENDY E HOY ${ }^{3}$ \\ ${ }^{1}$ Department of Anatomy and Cell Biology, Monash University, Clayton, Victoria, 3800, Australia, \\ ${ }^{2}$ Department of Pathology, University of Mississippi Medical Center, Jackson, MS, USA, ${ }^{3}$ Menzies School of \\ Health Research, Casuarina, Northern Territory, Australia, \\ ${ }^{\#}$ Current address: Howard Florey Institute of Experimental Physiology and Medicine, Royal Parade, Parkville, \\ Victoria 3052, Australia \\ e-mail: John.Bertram@med.monash.edu.au,k.johnson@hfi.unimelb.edu.au, \\ Mhughson@pathology.umsmed.edu, wendy@kdrp.org \\ (Accepted August 23, 2001)
}

\begin{abstract}
End stage renal disease is a major health problem for Australian Aborigines and African Americans. Abnormally enlarged glomeruli are commonly observed in biopsies from Aborigines and African Americans and may represent a compensatory hypertrophic response to reduced nephron endowment. We have commenced a study examining glomerular number and size, and their associations in Australian Aborigines and whites, and US African Americans and whites. Kidneys at autopsy are perfusion-fixed and subsampled for stereological estimation of total glomerular number $\left(\mathrm{N}_{\text {glom }}\right.$; using the physical disector/fractionator combination), and mean renal corpuscle $\left(\mathrm{V}_{\text {corp }}\right)$ and glomerular volume $\left(\mathrm{V}_{\text {glom }}\right)$. Kidneys from 58 people have been studied to date with ages ranging from newborn to 84 years. Preliminary findings are: (1) an almost 9-fold range in $\mathrm{N}_{\text {glom }}$ (from 210,332 to 1,825,380) with a mean of 762,302; (2) $\mathrm{N}_{\text {glom }}$ decreased with age in adult life ( $\mathrm{p}=0.014$ ); (3) $\mathrm{V}_{\text {corp }}$ varied 19-fold in the series and 5.5-fold in adults; (4) $\mathrm{V}_{\text {glom }}$ was inversely correlated with $\mathrm{N}_{\text {glom }}(\mathrm{p}=0.004)$; (5) total renal corpuscle volume $\left(\mathrm{N}_{\text {glom }} \times \mathrm{V}_{\text {corp }}\right)$ ranged by a factor of 13.2; (6) kidney weight was correlated with body surface area (BSA) at all ages (p <0.001); (7) BSA-corrected kidney weight did not vary with age, it ranged from $47 \mathrm{~g} / \mathrm{m}^{2}$ to $175 \mathrm{~g} / \mathrm{m}^{2}$, a 3.7 fold difference, with an average of $92 \pm 25 \mathrm{~g} / \mathrm{m}^{2}$. These preliminary results have revealed several new and important correlations. No racial differences in glomerular number or size have yet been identified, but with greater sample sizes such differences may be revealed.
\end{abstract}

Keywords: African Americans, Australian Aborigines, glomerular number, kidney.

\section{INTRODUCTION}

End stage renal disease (ESRD) is a major health problem for Australian Aborigines, with the incidence nationwide being approximately 10 times that observed in the non-Aboriginal population. For Aborigines in the Northern Territory the incidence of ESRD is 20-times that of non-Aborigines. Indeed, ESRD has reached such epidemic proportions in the Northern Territory, that though Aborigines comprise only approximately $22 \%$ of the total population they constitute $95 \%$ of people on renal dialysis. A high rate of ESRD is also observed in African Americans whose rate of ESRD is approximately 4 times that of Caucasian Americans (Blythe and Maddox, 1991; US Renal Data System, 1994).
Glomerulomegaly (abnormally enlarged glomeruli) is a common finding in renal biopsies from Australian Aborigines (Howard et al., 1996; Moore et al., 1996; Bertram et al., 1998) and African Americans (Pesce et al., 1994), although we have recently found a difference in glomerular size between African and white Americans in patients biopsied for renal disease to be not significant. The cause of the glomerular enlargement is unknown. It may represent a compensatory hypertrophic response secondary to reduced nephron endowment (abnormal or limited nephrogenesis) during fetal development, and/or the response to trophic and stimulatory factors encountered in postnatal life. Intrauterine malnutrition and possibly environmental/ historic adaptation are likely causes of the first, and abnormal haemodynamic and metabolic 
profiles (Syndrome X) and chronic and repeated infections are likely causes of the latter. In Aborigines, who have persistently low birth weights as well as increasing rates of hypertension, type 2 diabetes and cardiovascular disease, the correlation of renal disease with both these early and late life influences are very strong. In African Americans the later life influences on renal disease are clear, but the relationship to birth weight, which remains below the US average, has not been studied.

We have commenced a multi-centre study aimed at determining the following renal parameters and correlations for Australian Aborigines and African Americans, and Caucasian populations from the same geographic regions: glomerular, and thereby nephron number; the relationships between glomerular number, age, sex and race; and the relationships between glomerular number, glomerular size and body size. Stereology is being used to estimate total glomerular, and thereby nephron number $\left(\mathrm{N}_{\text {glom }}\right)$, as well as glomerular $\left(\mathrm{V}_{\text {glom }}\right)$ and renal corpuscle $\left(\mathrm{V}_{\text {corp }}\right)$ volume. We here report data from the first 58 kidneys analyzed in this prospective study.

\section{MATERIALS AND METHODS}

Kidneys were collected at autopsy at the Royal Darwin Hospital (Darwin, Northern Territory) and at the University of Mississippi Medical Center (Jackson, Mississippi), weighed, sampled for stereology and then mailed to Monash University where they were processed for embedding in glycolmethacrylate for stereological estimation of total glomerular number using the physical disector/fractionator combination, glomerular volume and renal corpuscle volume. These methods have been described in detail in Bertram et al. (1992), Bertram (1995) and Johnson et al. (2000).

The 58 kidneys came from people aged from 3 days to 85 years $(35.7 \pm 19.9$ years; mean $\pm \mathrm{SD})$, with 48 being adults (18 years and older). The numbers of females, children and Australian Aborigines are small. There is only one person under 18 years in the Australian sample and only two females. There is not equal representation in various age groups. Therefore, the conclusions drawn at this stage should be considered preliminary. Nevertheless, some strong relationships are apparent and other important correlations are suggested.

\section{RESULTS}

Data are summarised in Table 1 (mean $\pm \mathrm{SD}$ ).

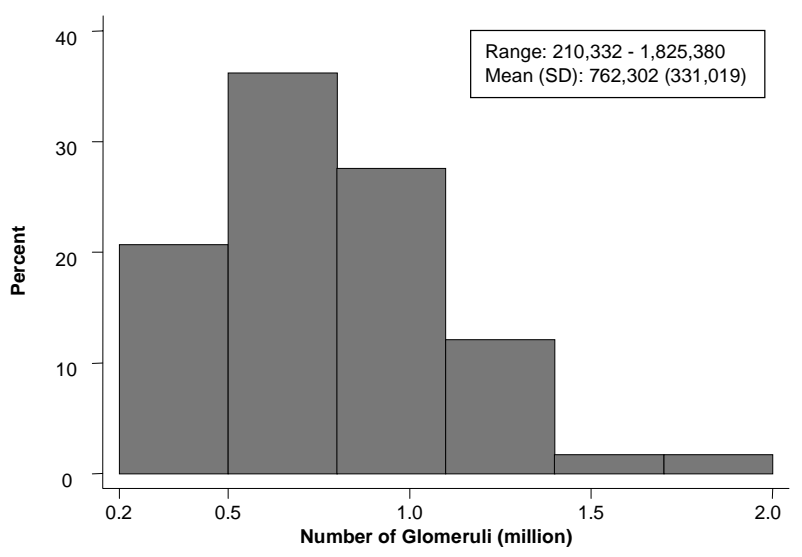

Fig. 1. Distribution of total glomerular number. Glomerular number ranges approximately 9-fold in the 58 kidneys analysed to date.

A 9-fold range in glomerular number was observed (from 210,332 in a 3 year African American male to $1,825,380$ in a 20 year African American male), with the average number being 762,302 (Fig. 1). Glomerular number was normally distributed. Glomerular number decreased with age in adult life $(p=0.014)$. It was not significantly correlated with body size in adults $(\mathrm{p}=0.884)$ and was similar in the four racial groups.

Mean glomerular (renal corpuscle) volume varied 19-fold in the series and 5.5-fold in adults, and was normally distributed. Mean glomerular volume ranged from $1.03 \times 10^{6} \mu \mathrm{m}^{3}$ in a 3 day American white male to $19.55 \times 10^{6} \mu^{3}$ in a 21 year African American male. Mean glomerular volume was inversely correlated with glomerular number ( $\mathrm{p}=0.004$; Fig. 2$)$ and increased strongly with BSA in childhood $(\mathrm{p}<0.001)$. Mean glomerular volume was similar in the four racial groups.

Total glomerular (renal corpuscle) volume (the product of glomerular number and average glomerular volume) ranged by a factor of 13.2, was lowest in children, peaked in early adult life and declined with age thereafter. Total glomerular volume was significantly correlated with BSA in children $(\mathrm{p}<0.001)$. There was no significant difference in total glomerular volume between the four racial groups. 


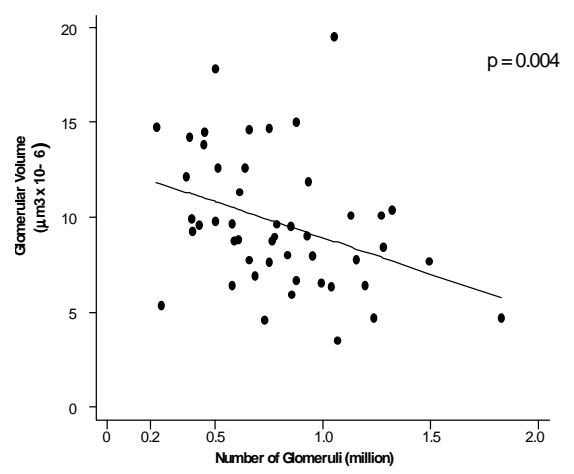

Fig. 2. Correlation between mean glomerular volume and glomerular number. In adults, glomerular number was the only significant determinant of glomerular size.

Kidney weight increased with age in children $(\mathrm{p}<0.001)$; was correlated with BSA at all ages ( $p<0.001)$; was about $12 \%$ lower in adult females than males; and was lower in Australian Aborigines than non-Aborigines $(p=0.009)$ but the correlation lost significance after adjusting for BSA (which was much lower in Aborigines). When data for Aborigines and African Americans were combined, their kidney weight was significantly lower than in whites $(\mathrm{p}=0.005)$, and the effect persisted after adjustment for age, sex and BSA. The difference seems to be not in glomerular number or total glomerular volume but rather in a lower rate of increase of extra-glomerular tissue with increasing BSA in blacks than in whites (Fig. 3). On average, the whites in our study gained an extra $111 \mathrm{~g}$ of extraglomerular tissue for each $\mathrm{m}^{2}$ increase in BSA ( $p=0.002)$, whereas the blacks only gained $33 \mathrm{~g}$ per $\mathrm{m}^{2}$ of BSA $(\mathrm{p}=0.154)$.

BSA-corrected kidney weight did not vary with age, it ranged from $47 \mathrm{~g} / \mathrm{m}^{2}$ to $175 \mathrm{~g} / \mathrm{m}^{2}$, a 3.7 fold difference, with an average of $92 \pm 25 \mathrm{~g} / \mathrm{m}^{2}$. BSAcorrected kidney weight was $20 \%$ lower in Australian Aborigines than non-Aborigines $(\mathrm{p}=0.155)$ and $7 \%$ lower in African Americans than in US whites (nonsignificant, $\mathrm{p}=0.64$ ).

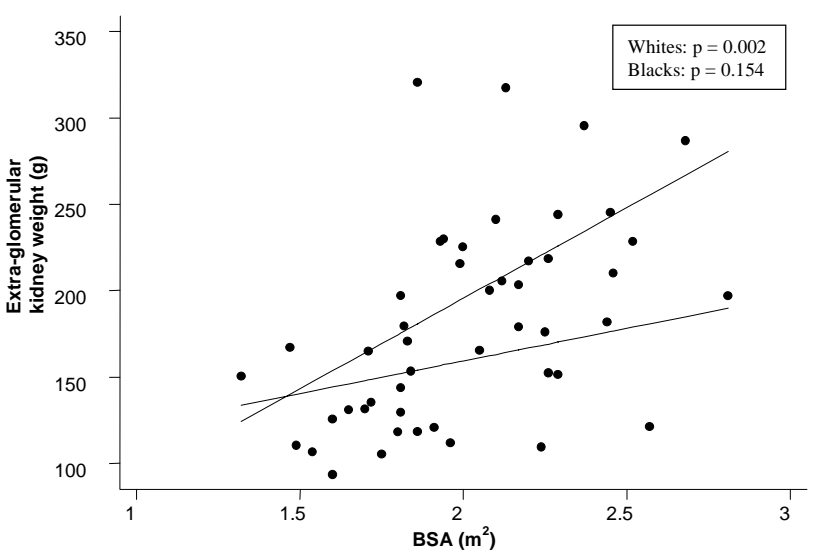

Fig. 3. Correlation between body surface area (BSA) and the weight of extra-glomerular tissue per kidney. Whites gain more extra-glomerular tissue for each $\mathrm{m}^{2}$ increase in BSA than Blacks.

Table 1. Data for the four racial groups. Values are mean $\pm S D$.

\begin{tabular}{|c|c|c|c|c|c|}
\hline & & $\begin{array}{c}\text { Australian } \\
\text { Aborigines }\end{array}$ & $\begin{array}{l}\text { Australian } \\
\text { Whites }\end{array}$ & $\begin{array}{c}\text { African } \\
\text { Americans }\end{array}$ & US Whites \\
\hline$\overline{\mathrm{N}}$ & & 7 & 13 & 24 & 14 \\
\hline Age & (yrs) & $34.1 \pm 11.9$ & $46.7 \pm 19.5$ & $33.6 \pm 19.7$ & $29.9 \pm 21.2$ \\
\hline Glomerular number & $\left(\times 10^{3}\right)$ & $761 \pm 291$ & $866 \pm 367$ & $761 \pm 365$ & $668 \pm 246$ \\
\hline Mean glomerular volume & $\left(\times 10^{6} \mu \mathrm{m}^{3}\right)$ & $8.83 \pm 2.39$ & $8.83 \pm 2.23$ & $8.91 \pm 4.90$ & $7.96 \pm 5.13$ \\
\hline Total glomerular volume & $\left(\mathrm{cm}^{3}\right)$ & $6.40 \pm 2.48$ & $7.34 \pm 3.02$ & $6.57 \pm 4.33$ & $5.25 \pm 4.08$ \\
\hline BSA & $\left(\mathrm{m}^{2}\right)$ & $1.61 \pm 0.19$ & $2.00 \pm 0.25$ & $1.80 \pm 0.68$ & $1.64 \pm 0.96$ \\
\hline Kidney weight & (g) & $141 \pm 20$ & $223 \pm 67$ & $150 \pm 66$ & $147 \pm 94$ \\
\hline Kidney weight/BSA & $\left(\mathrm{g} / \mathrm{m}^{2}\right)$ & $89.4 \pm 20.5$ & $111.1 \pm 30.2$ & $85.0 \pm 22.0$ & $91.7 \pm 18.1$ \\
\hline
\end{tabular}

\section{DISCUSSION}

These preliminary data have extended our knowledge of renal structure in the four racial groups, and revealed for the first time important correlations between renal parameters and indices of body dimensions. No significant racial differences in glomerular number or size have yet been identified, but with greater sample sizes such differences may be revealed.
One of the more unexpected findings from this preliminary study concerns the large range of values for total glomerular, and thereby, nephron number in human kidneys. In their landmark autopsy study of 37 Danish kidneys, Nyengaard and Bendtsen (1992) found a 3.2-fold range in glomerular number, compared to the almost 9-fold range reported in the present study. Interestingly, the mean values from the two studies are comparable: 762,302 (present study) and 617,000 (Nyengaard and Bendtsen, 1992). A physical disector/ 
fractionator combination was used to estimate nephron number in both studies. While the lowest estimate of nephron number in the two studies is somewhat similar $(210,332$ in the present study and 331,000 for Nyengaard and Bendtsen, 1992), the upper estimate is quite different. The highest estimate in the present study is $1,825,380$, whereas the highest estimate of Nyengaard and Bendtsen (1992) was 1,424,000. However, this value was excluded from the study because it deviated significantly from the other values. The next highest value was $1,056,000$. Interestingly, 10 of the present 58 estimates of glomerular number are higher than 1,056,000. There are many reasons for why the present estimates range widely, the principal one possibly being the fact that our estimates come from four racial groups.

Large ranges in glomerular volumes (19-fold) and renal corpuscle volumes (19-fold) were also observed in the present study. These compare with a 2.3 -fold range in mean glomerular volume in the Nyengaard and Bendtsen (1992) study. As indicated above, glomerular hypertrophy is a characteristic of diseased renal biopsies from Australian Aborigines and African Americans, and may well underlie this large range in glomerular size.

The finding that total glomerular number is strongly correlated with mean glomerular volume is important, because it lends support to the hypothesis that reduced glomerular number, whatever the cause (and speculation goes well beyond birth weight and the intrauterine environment), is a powerful determinant of glomerular volume in adults.

The preliminary finding that the increase in mass of extra-glomerular tissue per $\mathrm{m}^{2} \mathrm{BSA}$ in whites is greater than in blacks is unexpected. This may indicate that hypertrophy of extra-glomerular tissue (tubules and interstitium) in response to increasing BSA is more limited in blacks than in whites. Clearly, this important preliminary finding needs to be confirmed once a larger sample of kidneys has been studied.

In conclusion, the present findings have confirmed some previous findings, identified some new and important correlations, and suggested some correlations that may emerge as statistically significant once additional kidneys have been analyzed. We estimate that more than 400 kidneys require analysis in order to complete this study. Clearly, the ability of the stereological techniques employed to provide accurate and precise estimates of glomerular number and volume is critical to the success of this project.

\section{ACKNOWLEDGEMENTS}

The authors gratefully acknowledge the support of the National Health and Medical Research Council (Australia), the Australian Kidney Foundation, and Janssen-Cilag Pty. Ltd.

\section{REFERENCES}

Bertram JF (1995). Analyzing renal glomeruli with the new stereology. Int Rev Cytol 161:111-72.

Bertram JF, Soosaipillai M, Ricardo SD, Ryan GB (1992). Total numbers of glomeruli and individual glomerular cell types in the normal rat kidney. Cell Tissue Res 270:37-45.

Bertram JF, Young RJ, Seymour AE, Kincaid-Smith P, Hoy W (1998). Glomerulomegaly in Australian Aborigines. Nephrology 4:S46-S53.

Blythe WB, Maddox FW (1991). Hypertension as a causative diagnosis of patients entering end-stage renal disease programs in the United States from 1980 to 1986. Am J Kidney Dis 18:33.

Howard DM, Davis J, Pugsley DJ, Seymour AM, Hoy WE (1996). Morphologic correlates of renal disease in a high risk Australian Aboriginal community. Proc $32^{\text {nd }}$ Annual Meeting of the Aust and NZ Soc Nephrology. Kidney International 1997;51(4):1318.

Johnson K, Wreford NG, Hoy WE, Bertram JF (2000). Estimating total glomerular number in human kidneys with a physical disector/fractionator combination. Image Anal Stereology 19:105-8.

Moore L, Lloyd MS, Pugsley DJ, Seymour AE (1996). Renal disease in the Australian Aboriginal population: a pathological study. Nephrology 2:315-21.

Nyengaard JR, Bendtsen TF (1992). Glomerular number and size in relation to age, kidney weight, and body surface in normal man. Anat Rec 232:194-201.

Pesce CM, Schmidt K, Fogo A, Okoye MI, Kim R, Striker LJ, Striker GE (1994). Glomerular size and the incidence of renal disease in African Americans and Caucasians. J Nephrol 7:355-8.

United States Renal Data System: USRDS (1994). Annual Data Report. Bethesda, MD, The National Institutes of Health, The National Institutes of Diabetes and Digestive and Kidney Diseases. 